\title{
Development and Evaluation of On-Line Nanoliter Flow Analysis of Protein Digests by Pneumatic-Splitter Electrospray Liquid Chromatography Mass Spectrometry
}

\author{
John C. Le, John Hui, Mitsuru Haniu, Viswanatham Katta, and \\ Michael F. Rohde \\ Department of Protein Structure, Amgen Center, Amgen Inc., Thousand Oaks, California, USA
}

\begin{abstract}
We have developed a novel approach to characterize protein digests by pneumatic-splitter electrospray ionization liquid chromatography mass spectrometry (PSESI-LCMS). This technique involves an interfacing of a pneumatic splitter that can dynamically generate and control a steady split flow rate of nanoliters per minute. An average PSESI-LCMS analysis, depending on the desired split ratio, consumes less than 200 femtomoles of sample. A tryptic digest map of a glycoprotein, fetuin, and a Lys-C digest map of a recombinant neurotrophin protein, neurotrophin-3, are reported here for this investigation. (J Am Soc Mass Spectrom 1997, 8, 703-712) (C) 1997 American Society for Mass Spectrometry
\end{abstract}

$\mathrm{E}$ lectrospray mass spectrometry [1] and recent developments of microspray and nanospray interfaces for an electrospray ionization source enhanced the sensitivity of analyses of proteins to the subfemtomole (sub fmol) level. Improvement in these techniques is perhaps governed by two operating principles: first, in order to obtain maximum transfer efficiency of the sample, the electrospray needle is placed as close as possible to the nozzle orifice of an electrospray source $[2,3]$; second, the lifetime of the ion of interest is sustained by a combination of ionization modes and mass analyzer [4]. Unfortunately, these techniques often require sample purity and freedom from solvent interferences, which are rare for proteins in biological samples.

This article focuses on the development and evaluation of pneumatic-splitter electrospray liquid chromatography mass spectrometry (PSESI-LCMS). This technique is achieved by interfacing a pneumatic splitter operating under a regulated pressure, with a conventional LCMS system. Neither high performance liquid chromatography (HPLC) nor electrospray mass spectrometer (MS) needs modification. This technique minimizes the equilibration time between analyses since analytical and narrow bore columns are preferred. Once a steady split flow rate of $\sim 1.6 \mu \mathrm{L} / \mathrm{min}$ or less is established by the pneumatic splitter, we have found that the maximum transfer efficiency of the sample can easily be achieved by placing the ion-spray needle within $1-4 \mathrm{~mm}$ of the orifice nozzle. This latter step

Address reprint requests to John C. Le, Department of Protein Structure, Amgen Center, MS 14-2-E, Amgen Inc., Thousand Oaks, CA 91320-1789. allows high sensitivity analysis of a protein digest to reach sub fmol (consumed) levels, and the major portion of sample can be collected fractionally for additional studies.

\section{Experimental}

The HPLC system consisted of a HP-1090 (HewlettPackard, Palo Alto, CA) high performance liquid chromatograph equipped with either a Vydac C-18 narrow bore column $(2.1 \mathrm{~mm} \times 15 \mathrm{~cm})$ or an analytical column $(4.6 \mathrm{~mm} \times 25 \mathrm{~cm})$ and operated at a flow rate of 250 or $500 \mu \mathrm{L} / \mathrm{min}$, respectively. For bovine fetuin analysis, the solvent composition of $0.065 \%$ aqueous trifluoroacetic acid (TFA) (solvent A) and acetonitrile/water (9:1) incorporating $0.05 \% \mathrm{TFA}$ (solvent $\mathrm{B}$ ) was linearly increased (from $5 \%$ of solvent B) at a rate of $0.65 \%$ of solvent $\mathrm{B} / \mathrm{min}$ for the first $70 \mathrm{~min}$ of an $80 \mathrm{~min}$ gradient. For neurotrophin-3, the solvent composition of $0.1 \%$ aqueous TFA (A) and acetonitrile/water (9:1) incorporating $0.1 \%$ TFA (B) was linearly increased (from $2 \%$ of solvent $\mathrm{B}$ ) on an analytical column at the rate of $0.80 \%$ of solvent $\mathrm{B} / \mathrm{min}$ for the first $60 \mathrm{~min}$ of an $80 \mathrm{~min}$ gradient.

A modified JEOL (Tokyo, Japan) MS-PNS pneumatic splitter was installed at the column outlet after the UV detector of an HPLC system. Most of the eluent was diverted to a collector via a release valve that worked at a predetermined pressure. This pressure was regulated to compensate for the back pressure caused by viscosity of mobile phase and the resistance of the fused silica tubing used to couple the release valve and the pneumatic splitter [5]. Under 0.35 or $0.65 \mathrm{~kg} / \mathrm{cm}^{2}$ pressure of 
highly pure nitrogen, the HPLC column eluent was split by a pneumatic splitter to deliver a constant flow of $-850 \mathrm{~nL} / \mathrm{min}$ (from a narrow bore column) or -1.6 $\mu \mathrm{L} / \mathrm{min}$ (from an analytical column). The split eluent flowed through an approximately $45 \mathrm{~cm}$ length of fused silica tubing ( $50 \mu \mathrm{m}$ i.d.; Polymicro Technologies, Phoenix, AZ) that threaded to the tip of an ion-spray needle of a Sciex API 100 or III mass spectrometer (Ontario, Canada). With a few modifications, we believe the split flow can be controlled to perhaps less than $150 \mathrm{~nL} / \mathrm{min}$.

For our current LCMS system, there is an $\sim 20$ s delay in the retention time between the UV trace (HPLC) and the total ion chromatogram (TIC) trace (MS). This delay is normally associated with all LCMS analyses due to the extra volume of tubing connecting the flow cell and the Valco " $\mathrm{T}$ " union or the pneumatic splitter. Because the volume of silica capillary tubing is $\sim 883 \mathrm{~nL}$, we anlicipated each eluent peak would be delayed by about $1 \mathrm{~min}$. By contrast, for the PSESI-LCMS, all eluent peaks appearing in the TIC trace were within $40 \mathrm{~s}$ of their UV trace. This increase of only $20 \mathrm{~s}$ compared to the TIC trace of typical ESI-LCMS indicates that eluent flow may be influenced by the pressure of the pneumatic splitter. This observation was first verified by measuring the volume of the eluent per period of time in triplicate. At either $5 \%$ or $50 \%$ solvent $B$, the average split flow rate was consistently $\sim 850 \mathrm{~nL} / \mathrm{min}$ ( $\pm 3 \%$ ). Second, unlike the conventional split flow, the " $\mathrm{T}$ " union of the pneumatic splitter was constantly under pressure of nitrogen gas $\left(0.35 \mathrm{~kg} / \mathrm{cm}^{2}\right.$, this study). Thus, it was reasonable to speculate that nitrogen gas could also compress a portion of the capillary tubing that followed immediately after the " $\mathrm{T}$ " union of the pneumatic splitter. If this were the case, the actual volume of the eluent that occupied the capillary tubing should be less than $883 \mathrm{~nL}$. Perhaps this explains why the elution time of each peak (TIC) was earlier than expected.

At present, standard plot of split flow rate $(\mathrm{nL} / \mathrm{min})$ versus pressure $\left(\mathrm{kg} / \mathrm{cm}^{2}\right)$ for different sizes of columns and dimensions of capillary tubing at flow rates of $\sim 250,450$, and $850 \mathrm{~nL} / \mathrm{min}$ are being validated. This step will eventually eliminate the need for manually measuring the split flow rates of other analyses.

The protein concentrations of "stock solutions" were determined by amino acid analysis to be 2.7 and 2.9 $\mathrm{pmol} / \mu \mathrm{L}( \pm 10 \%)$ for bovine fetuin and neurotrophin-3 (NT-3), respectively. Each PSESI-LCMS analysis of bovine fetuin sample was performed using a dilution of 5 $\mu \mathrm{L}$ of "stock solution" with $50 \mu \mathrm{L}$ of water/acetonitrile (99:1) incorporating $0.1 \%$ formic acid (solvent C). Only $50 \mu \mathrm{L}$ of this aliquot was analyzed $(\sim 12 \mathrm{pmol} / \mathrm{injec}-$ tion). For PSESI-LCMS analysis of NT-3 each sample was prepared by diluting $16 \mu \mathrm{L}$ of its "stock solution" with $90 \mu \mathrm{L}$ of $0.1 \%$ aqueous TFA. Only $100 \mu \mathrm{L}$ of this aliquot was analyzed ( $\sim 45 \mathrm{pmol} /$ injection). A similar procedure was applied to prepare samples for ESILCMS analysis.

A tryptic digest of bovine fetuin glycoprotein $(-50$ $\mathrm{kDa}$ ) was obtained according to the procedure of
Medzihradszley et al. [6] with few modifications. Bovine fetuin glycoprotein (359 amino acid residues) was purchased from Sigma Cherrical Co. (St. Louis, MO) and used without purification. Ammonium acetate was uscd to adjust the $\mathrm{pH}$ to 8.0 of the digest mixture. There was no further addition of trypsin after $2.5 \mathrm{~h}$ of incubation. This digest mixture was further diluted with 5 $\mathrm{mL}$ of solution $\mathrm{C}$ and stored at $-80^{\circ} \mathrm{C}$ until use. An I.ys-C digest of an $E$. coli expression recombinant human NT-3 $(\sim 14 \mathrm{kDa})$, a member of the nerve growth factor family of neurotrophic factors, was obtained according to a known procedure [7].

A mixture consisting of polypropylene glycol (PPG) $1000\left(1 \times 10^{-4} \mathrm{M}\right)$ and $2000\left(2 \times 10^{-4} \mathrm{M}\right)$ in 50:50:0.1 water/methanol/formic acid $(\mathrm{v} / \mathrm{v} / \mathrm{v})$ was used for the tuning and calibration of the mass spectrometers. The range $m / z 10-2400$ was calibrated in the positive ion mode by multiple-ion monitoring of eight PPG ion signals (isotope clusters). Depending on the charge state and the isotopic distribution, the mass-to-charge ratios in all the figures were assigned by the measured peak tops that were either closer to the monoisotopic or to the average mass-to-charge ratio. All mass data were tabulated using Sciex BioMultiview 1.2. Myoglobin ([M + $\mathrm{HJ}^{+}$avg. $\left.=16951 \pm 1.5 \mathrm{Da}\right)$ was used as an external calibrant of the mass spectrometers.

Mass spectra of bovine fetuin analyses were acquired over a range from $\mathrm{m} / \mathrm{z} 450-2200$ at $7 \mathrm{~s} / \mathrm{scan}$ in $0.25 \mathrm{~m} / \mathrm{z}$ steps. The nebulizer gas (air) and curtain gas $\left(\mathrm{N}_{2}\right)$ were set at 0.5 and $0.6 \mathrm{~L} / \mathrm{min}$, respectively. The ion-spray needle voltage was $5000 \mathrm{~V}$ for ESI-LCMS. Mass spectra during NT-3 analyses were acquired over a range from $\mathrm{m} / \mathrm{z} 400-2200$ at $5 \mathrm{~s} / \mathrm{scan}$ in $0.25 \mathrm{~m} / \mathrm{z}$ steps. The nebulizer gas (air) and curtain gas $\left(\mathrm{N}_{2}\right)$ were set at 0.6 and $0.7 \mathrm{~L} / \mathrm{min}$, respectively.

Like another "nano-ESI" technique [3] that we have examined, fine tuning the ion-spray needle position and voltages enhanced the performance of this PSESI-LCMS technique. For each PSESI-LCMS analysis of bovine fetuin at a split flow rate of $\sim 850 \mathrm{~nL} / \mathrm{min}$, we found that the ion current was reduced when the potential of the ion-spray needle was outside a $3500 \pm 50 \mathrm{~V}$ range. However, in the case of N'I-3 analysis by PSESI-LCMS, the optimal voltage needle was $3800 \pm 100 \mathrm{~V}$, perhaps due to a higher split flow rate. Although these capillary potentials were $\sim 2000 \mathrm{~V}$ higher than other low flow techniques $[3,8,9]$, they were within the ion-spray needle voltages (2000-3500 V) of the microelectrospray developed by Emmett and Caprioli [10]. We believe these capillary voltages $(3500 \pm 50 \mathrm{~V}$ and $3800 \pm 100 \mathrm{~V})$ were indeed necessary for the PSESI-LCMS analyses reported here to offset the voltage drop between the tip of the spray needle and the spray union of the Sciex electrospray mass spectrometers (M. Vestal, personal communication). We also anticipate that the optimal needle voltage would vary with different dimensions of the capillary tubing and further reduction of the split flow rates. 

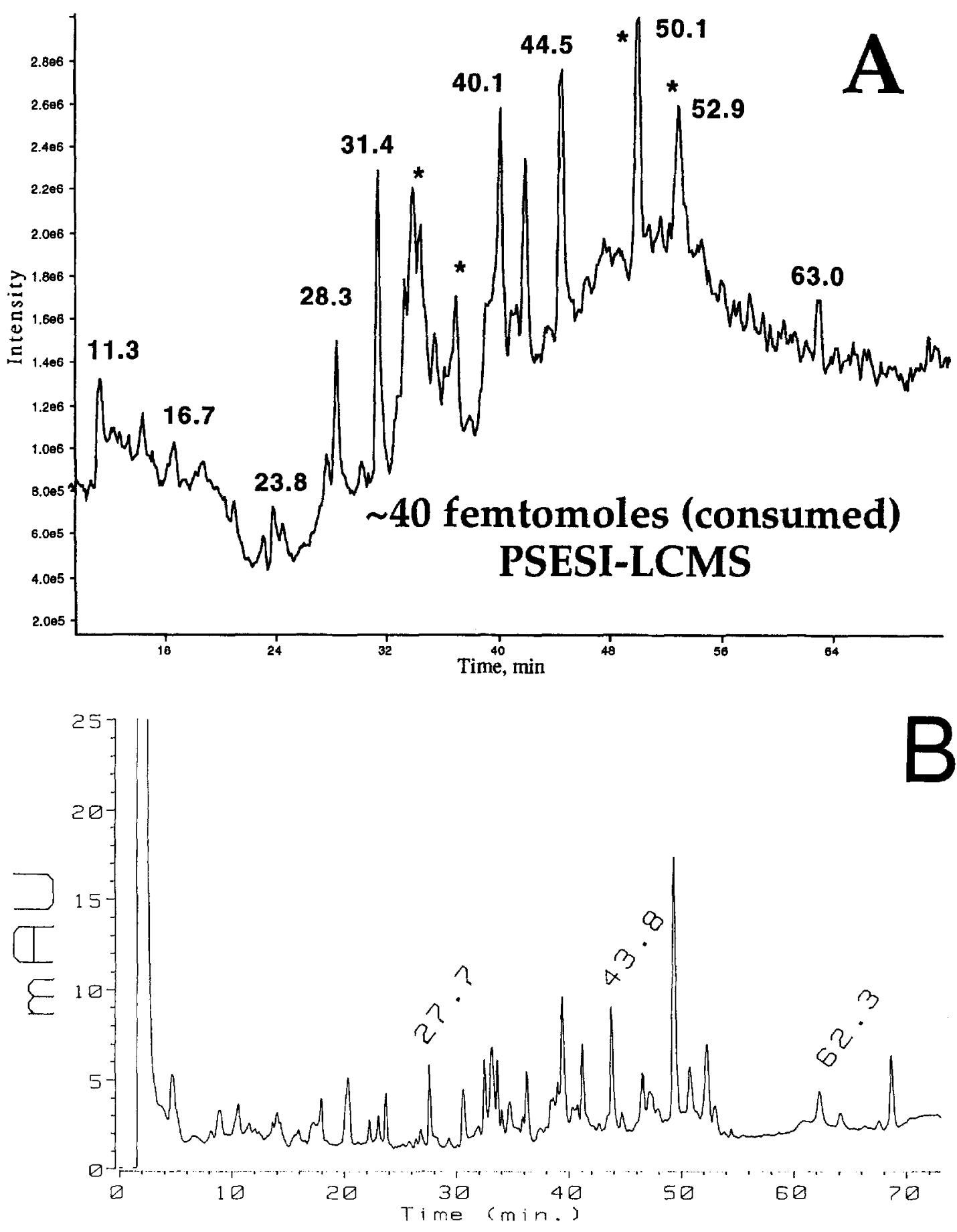

Figure 1. Panel $\mathrm{A}$ is a reconstructed TIC of $\sim 40 \mathrm{fmol}$ (consumed) bovine fetuin tryptic digest by PSESI-LCMS with a split ratio of $\sim 300: 1$. (*) indicates glycopeptides. Panel B is the IIPLC-UV trace from an injection of $-12 \mathrm{pmol}$. The flow rate was $250 \mu \mathrm{L} / \mathrm{min}$ before splitting.

\section{Results and Discussion}

Panel A of Figure 1 shows a reconstructed TIC of $\sim 40$ fmol (consumed) of bovine fetuin tryptic digest by PSESI-I.CMS analysis using a narrow bore column. This was achieved with a split ratio of $\sim 300: 1$ by a pneumatic splitter to generate a flow rate of $\sim 850 \mathrm{~nL} / \mathrm{min}$. At this flow rate, we found the transfer efficiency of $\sim 40$ femtomoles of the above sample to be sufficient and maximized when the ion-spray needle was placed directly in front and $\sim 2.5 \mathrm{~mm}$ away from the orifice nozzle. This result showed that ion current could be increased greatly with much less sample if sample loss during the spray process was minimized $[2,3]$. Panel B of Figure 1 shows the UV trace of the above PSESILCMS for comparison. 


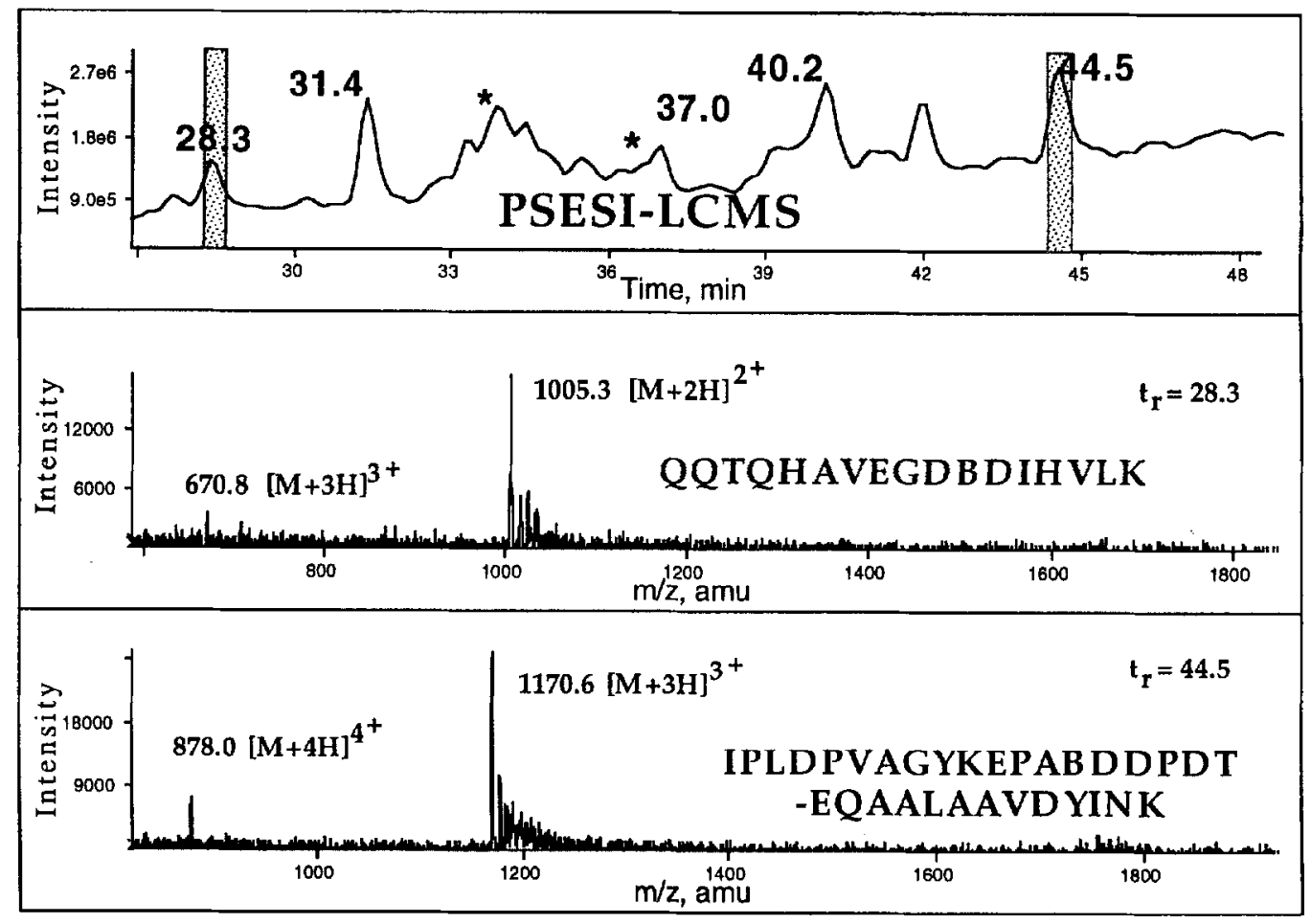

Figure 2. PSESI-LCMS mass spectra of a bovine fetuin peptide at $t_{r}=28.3 \mathrm{~min}$, where $[\mathrm{M}+2 \mathrm{H}]^{2+}$ $-m / z 1005.8$ and $[\mathrm{M}+3 \mathrm{H}]^{3+}-m / z 670.8$ (MW: $\left.2008.9 \mathrm{Da}\right)$, and a peptide al $\iota_{r}-44.5 \mathrm{~min}$, where $[\mathrm{M}+3 \mathrm{H}]^{3+}=m / z 1170.6$ and $[\mathrm{M}+4 \mathrm{H}]^{4+}=m / z$ 878.0 (MW: 3508.7 Da). These peptides correspond to residues (86-102) and (1-32), respectively [6].

Since the amino acid sequence of bovine fetuin and NT-3 has been characterized $[6,7,11]$, the purpose of this study was to confirm unambiguously the molecular weight of these peptides and glycopeptides to establish the increased sensitivity of this technique. Figure 2 shows PSESI-LCMS mass spectra of two peptides from bovine fetuin at $t_{r}=28.3 \mathrm{~min}$, where $[\mathrm{M}+2 \mathrm{H}]^{2+}=$ $m / z 1005.3$ and $[\mathrm{M}+3 \mathrm{H}]^{3+}=m / z 670.8$, corresponding to the sequence QQTQHAVFGDBDIHVI.K (MW: $2,008.9 \mathrm{Da})$, and at $t_{r}=44.5 \mathrm{~min}$, where $[\mathrm{M}+3 \mathrm{H}]^{3+}=$ $m / z \quad 1,170.6$ and $[\mathrm{M}+4 \mathrm{H}]^{4+}=m / z 878.0$, corresponding to the sequence IPLDPVAGYKEPABDDPDTEQAALAAVDYINK (MW: 3508.7 Da). Pyridylethyl cysteine is denoted as "B." These spectra were produced by averaging five scans (out of ten possible scans) from the apices of these TIC peaks. This implied that $40 \mathrm{fmol}$ (consumed) of sample were more than enough for detection by this technique. Satellite peaks of higher $\mathrm{m} / \mathrm{z}$ associated with more abundant ions in Figure 2 were attributed to sodium and potassium adduct ions.

Figure 3 shows a mass spectrum from the same PSESILCMS analysis of a glycopeptide from bovine fetuin at $t_{r}=50.1 \mathrm{~min}$. The average molecular mass, 6924.7 Da $\left([\mathrm{M}+4 \mathrm{H}]^{4+}=m / z 1732.1\right.$ and $[\mathrm{M}+5 \mathrm{H}]^{5+}=m / z$ 1386.5), corresponds to the sequence RPTGEVYDIEIDTLETTBHVLDPTPLANBSVR (54-85), where the Nlinked $A s{ }^{81}$ glycosylation site was identified (by mass only) as tetrasialo triantennary, $\mathrm{Hex}_{6} \mathrm{HexNAc}_{5} \mathrm{SA}_{4}[6]$. Other masses at $6630.6 \mathrm{Da},\left([\mathrm{M}+4 \mathrm{H}]^{4+}=m / z 1658.8\right.$ and $\left.[\mathrm{M}+5 \mathrm{H}]^{5+}=m / z 1327.0\right)$ and $6340.5 \mathrm{Da}([\mathrm{M}+$ $4 \mathrm{H}]^{4+}=m / z 1586.6$ and $\left.[\mathrm{M}+5 \mathrm{H}]^{5+}=m / z 1268.6\right)$, correspond to the above sequence, where the carbohydrate structures were identified (by mass only) as triand disialo triantennary oligosaccharides at $\mathrm{Asn}^{81}$, respectively. The mass of $5974.5 \mathrm{Da}\left([\mathrm{M}+4 \mathrm{H}]^{4+}=\mathrm{m} / z\right.$ 1494.8 and $\left.[\mathrm{M}+5 \mathrm{H}]^{5+}=m / z 1195.3\right)$, corresponding to the disialo biantennary oligosaccharide at $\mathrm{Asn}^{81}$, was not observed in one previous study [11], but was observed when a nontraditional mobile phase was used (water/ethanol/propanol/formic acid) [6]; it was clearly identified (by mass only) by this PSESI-LCMS analysis. Although this particular glycoform could not be detected during our use of conventional ESI-LCMS shown in this article (Figure $5, t_{r}=49.5 \mathrm{~min}$, data not shown), its mass has been observed at a higher consumed level ( $>25$ pmol, data not shown) by conventional ESI-LCMS using the same solvent system reported here for PSESI-LCMS. Most of the other glycopeptides of bovine fetuin have also been identified (by mass only) and agree with previous reports [6, 11]. Higher mass satellite peaks (Figure 3 ) were again attributed to sodium and potassium adduct ions.

With the exception of glycopeptides, chromatographic peak shapes of all components appeared normal. However, the baseline of the TIC trace (Panel A of Figure 1) was relatively high. The remedies for this nuisance were to lower the split flow rate $(\sim 300 \mathrm{~nL} /$ min or less) and to position the ion-spray needle even 


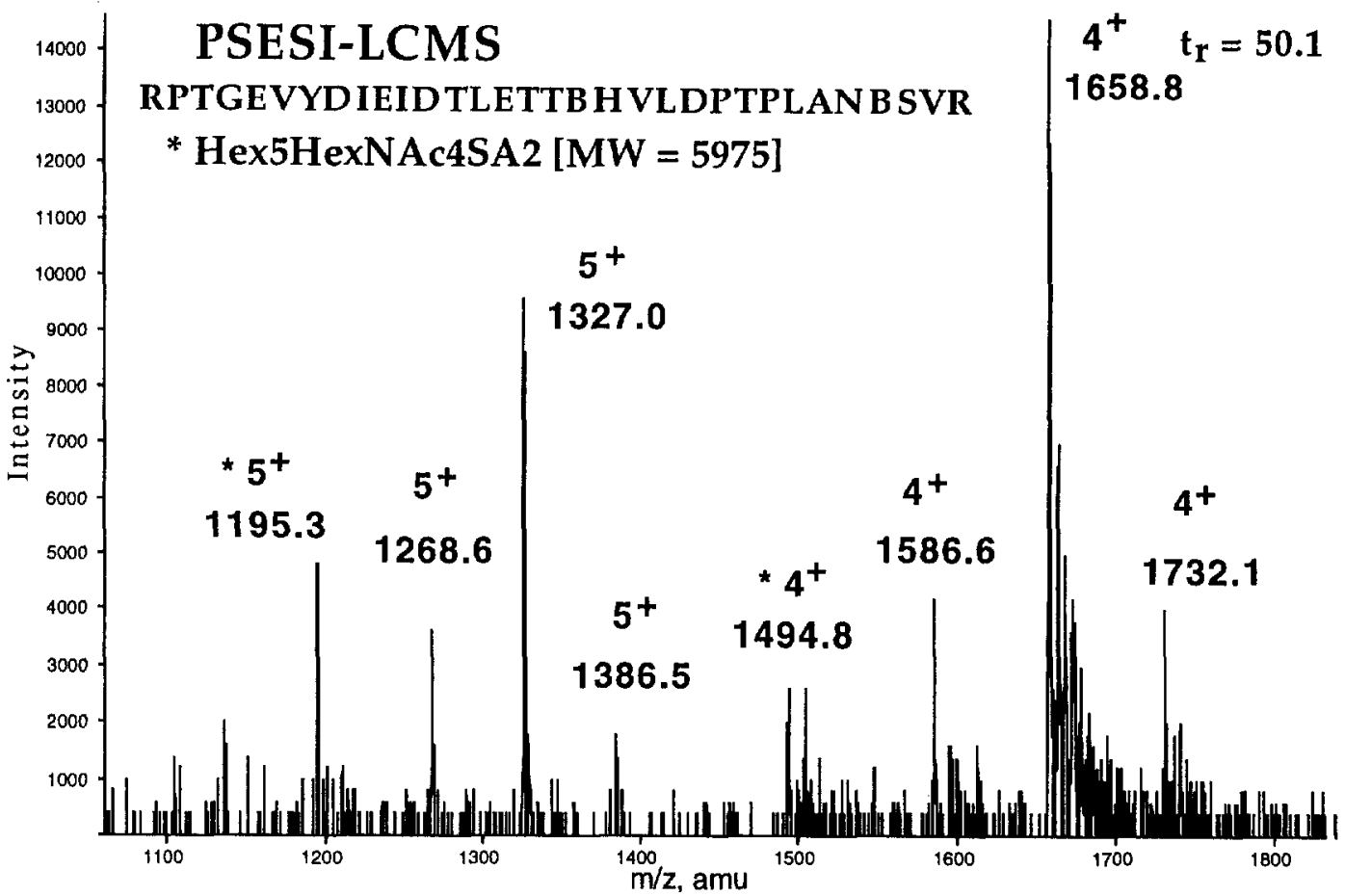

Figure 3. PSESI-LCMS mass spectrum of a glycopeptide at $t_{r}=50.1 \mathrm{~min}$ corresponding to residues (54-85) of bovine fetuin glycoprotein [6]. The corresponding molecular masses of these glycopeptide glycoforms, 6925.0, 6631.0, 6341.0, and 5974.5 Da represent tetra-, tri- and disialo triantennary and disialo biantennary substiuents at $\mathrm{Asn}^{81}$, respectively. The protonated ion series of the above subsequent glycoforms are $m / z 1732.1$ and 1386.5; 1658.8 and $1327.0 ; 1586.6$ and 1268.6; 1494.8 and 1195.3.
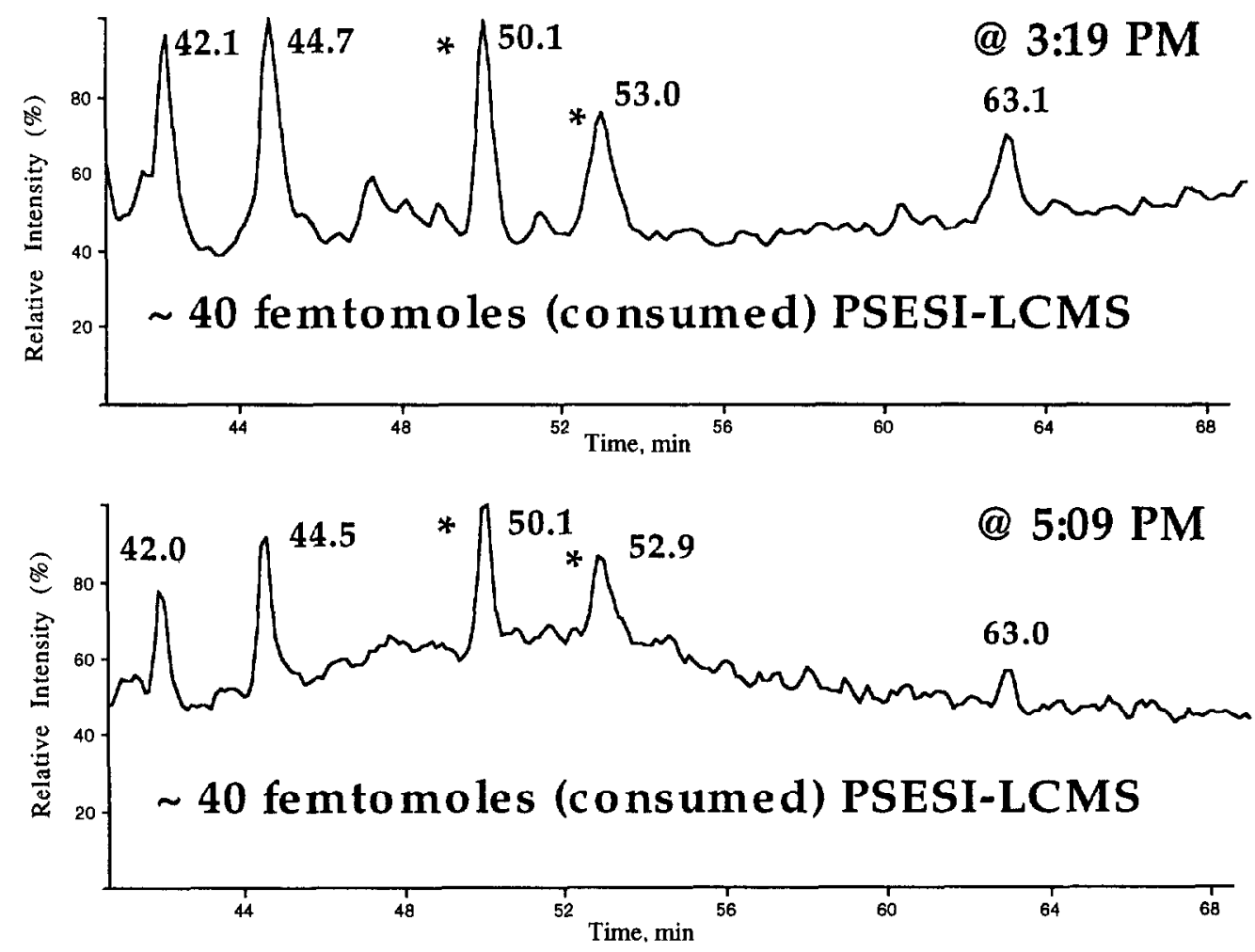

Figure 4. A reconstructed TIC of the last $30 \mathrm{~min}$ of each of two consecutive PSESI-LCMS analyses of bovine fetuin that extended over a period of $-3 \mathrm{~h}$. The average difference in the retention time of five major peaks was $-3 \mathrm{~s}$. 

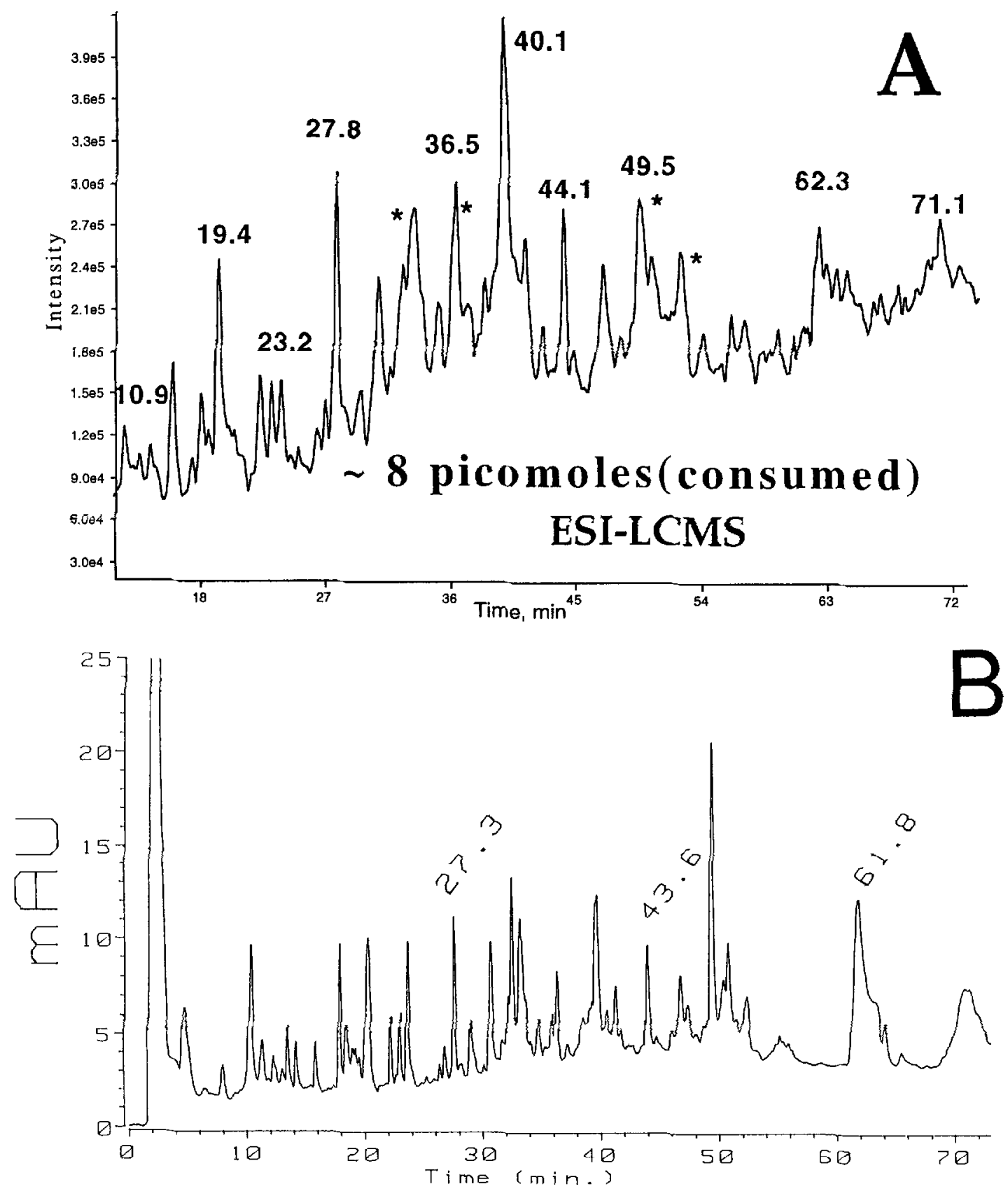

Figure 5. Panel $A$ is a reconstructed TIC of $\sim 8$ pmol (consumed) of bovine fetuin by conventional ESI-LCMS with a split ratio of 3:1. (*) indicates glycopeptides. Panel B is the HPLC-UV trace from an injection of $\sim 25$ pmol.

closer $(\sim 1 \mathrm{~mm})$ to the orifice nozzle; this step allows less solvent but a higher proportion of the analytes to be drawn into the analyzer. In addition, replacing the nebulizing gas with pure, dry $\mathrm{N}_{2}$ has also been suggested by Emmett and Caprioli [10]. Air was used as nebulizer gas for all analyses reported here.

Maintaining a consistent nL flow rate despite changes in viscosity of the solvent system is a unique feature of the pneumatic splitter. This feature has indeed contributed to the reproducibility of the PSESILCMS system. Figure 4 shows the TIC traces of the last 30 min of each of two consecutive PSESI-LCMS analy- ses that extended over a period of $\sim 3 \mathrm{~h}$. This period also included an 80-min blank analysis and two 15 min of column equilibration between analyses. The average difference in retention time of five major peaks (apex) was $-3 \mathrm{~s}$.

Panel A of Figure 5 shows a reconstructed TIC of a typical conventional ESI-LCMS analysis of $\sim 8 \mathrm{pmol}$ (consumed) of bovine fetuin for comparison. The flow rate was $250 \mu \mathrm{L} / \mathrm{min}$ and the HPLC column eluent was split by a 3:1 ratio. This split ratio was achieved with an appropriate length of PEEK (polyether ether ketone) tubing on a Valco "T" union. Panel B of Figure 5 shows 

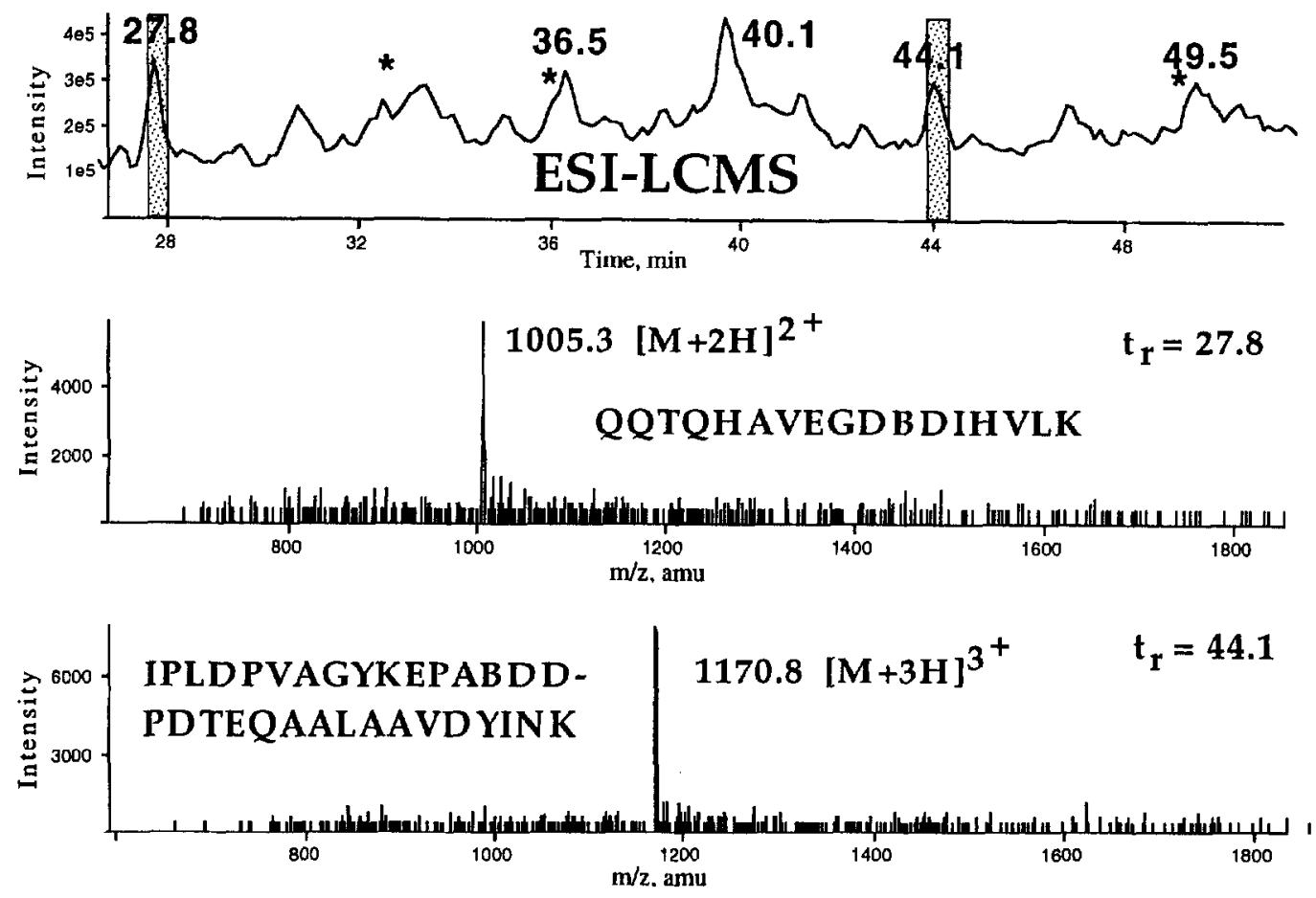

Figure 6. ESI-LCMS mass spectra of bovine fetuin peptides at $t_{r}=27.8$ and $44.1 \mathrm{~min}$, where $[\mathrm{M}+$ $2 \mathrm{H}]^{2+}=m / z$ 1005.3 (MW: 2008.6 Da) and $[\mathrm{M}+3 \mathrm{H}]^{3+}=m / z$ 1170.8 (MW: 3509.4 Da), corresponding to residues sequence (86-102) and (1-32), respectively [6]. " $\mathrm{B}$ " is pyridylethyl cysteine. The higher charge state ions $[\mathrm{M}+3 \mathrm{H}]^{3+}=\mathrm{m} / \mathrm{z} 670.8\left(t_{r}=27.8\right)$ and $[\mathrm{M}+4 \mathrm{H}]^{4+}=\mathrm{m} / \mathrm{z} 878.0$ $\left(t_{r}=44.1\right)$ of these peptides could not be detected at this consumption level.

the HPLC-UV trace of this analysis. A normal voltage of $5000 \mathrm{~V}$ was applied on the ion-spray needle that was placed at a $30^{\circ}$ angle and $\sim 7.0 \mathrm{~mm}$ away from the orifice nozzle. Under these conditions, $\sim 8$ pmol (consumed) appeared to be the minimum sample requirement to meet the detection limit of the mass spectrometer.

Figure 6 shows the mass spectra obtained by conventional ESI-LCMS for two bovine fetuin peptides at $t_{\text {, }}=$ $27.8 \mathrm{~min}$ and $t_{r}=44.1 \mathrm{~min}$ that were also examined by PSESI-LCMS (Figure 2). The intensities of ions [M+ $2 \mathrm{H}]^{2+}=m / z 1005.3$ and $[\mathrm{M}+3 \mathrm{H}]^{3+}=\mathrm{m} / z 1170.8$ were substantially weaker; also notice that the $[\mathrm{M}+$ $3 \mathrm{H}]^{3+}=m / z 670.8\left(t_{r}=27.8 \mathrm{~min}\right)$ and $[\mathrm{M}+4 \mathrm{H}]^{4+}=$ $\mathrm{m} / \mathrm{z} 878.0\left(t_{r}=44.1 \mathrm{~min}\right)$ ions could not be detected (at this consumption level). These spectra were produced by averaging five scans (out of eight possible scans) from the apices of these TIC peaks.

A PSESI-LCMS analysis of $\sim 200 \mathrm{fmol}$ (consumed) of NT-3 Lys-C digest is shown in panel A of Figure 7. This was achieved with a split ratio of $\sim 300: 1$ using the pneumatic splitter to provide a flow rate of $\sim 1.6$ $\mu \mathrm{L} / \mathrm{min}$. The ion-spray needle was placed directly in front and $\sim 3.5 \mathrm{~mm}$ away from the orifice nozzle. Panel $B$ of Figure 7 shows the HPLC-UV trace of this analysis. The retention time of the HPLC-UV trace was $\sim 2 \mathrm{~min}$ earlier than the corresponding TIC trace due to an acquisition delay in this analysis.

Figure 8 shows the mass spectrum of a peptide at $t_{r}=32.4 \mathrm{~min}\left([\mathrm{ll})\right.$, where $[\mathrm{M}+2 \mathrm{H}]^{2+}=m / z 856.4$ corresponds to the sequence TSQTYVRALTSENNK (82-96) derived from NT-3 protein. Similarly, the ions $[\mathrm{M}+\mathrm{H}]^{+}=m / z 778.2$ and $[\mathrm{M}+\mathrm{H}]^{+}=m / z 1035.4$ correspond to sequences MYAEHK (1-6) and NGJRGIDDK (66-74), respectively. These two peptides coeluted at $t_{r}=22.2 \mathrm{~min}$. Carboxymethyl cysteine is denoted as "J." The above peptides were also verified by Edman sequencing. These spectra were produced by the averaging of five scans (out of eleven possible scans) from the apices of these TIC peaks. A typical ESI-LCMS analysis of NT-3 has been reported elsewhere [7].

The above observed data provided us with two critical points relating to the early development of this technique. First, the high sensitivity analysis of $\sim 200$ fmol (consumed) of an entire protease digest was unprecedented, and was not previously observed in our laboratory. Second, the use of a new gradient system consisting of $0.065 \%$ aqueous TFA (A) and acetonitrile/ water (9:1) incorporating $0.05 \%$ TFA (B) was found necessary to stabilize the baseline of high sensitivity analyses such as those below the 50 pmol range [12]. The advantage of this gradient is apparent from a comparison of the HPLC-UV traces of panel B of Figures 1 and 5. The unstable baseline was observed for either bovine fetuin (data not shown) or NT-3 (panel B of Figure 7) analysis when a more conventional gradient system was used. Moreover, this solvent system enhanced the separation of peptides and glycopeptides 

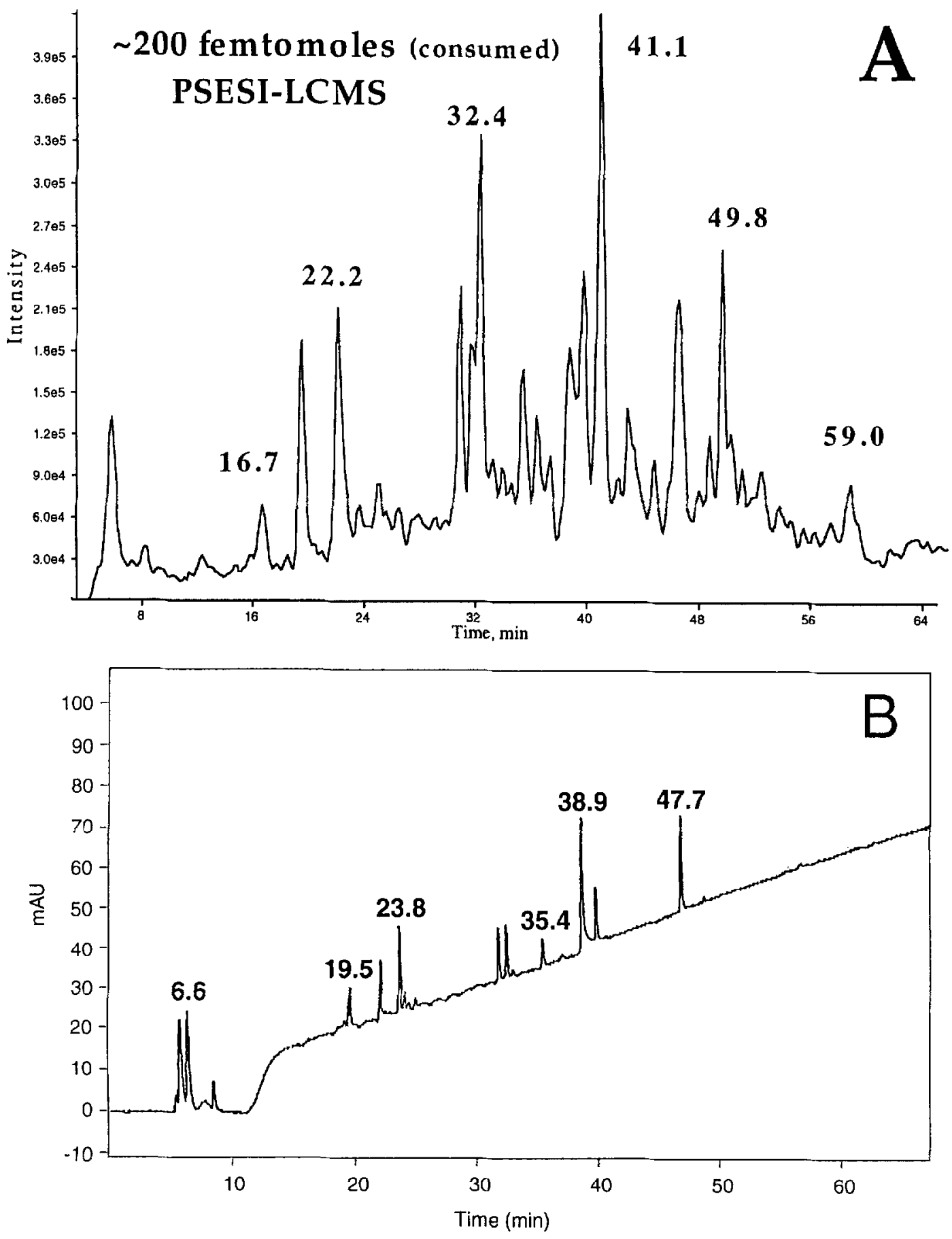

Figure 7. Panel A is a reconstructed TIC of $\sim 200 \mathrm{fmol}$ (consumed) of neurotrophin-3 (NT-3) Lys-C digest by PSESI-LCMS with a split ratio of $\sim 300: 1$. Panel B is the HPLC-UV trace from an injection of $\sim 45 \mathrm{pmol}$ of sample. The flow rate was $500 \mu \mathrm{L} / \mathrm{min}$ before splitting.

(to some extent) of bovine fetuin. Most important, the combination of these solvent solutions and the PSESILCMS has definitely enhanced the sensitivity for the identification of glycopeptides and their heterogeneity as discussed earlier.

The advantages of using postcolumn addition of propionic acid or the use of formic acid to enhance the sensitivity for peptide mapping have been reported by Fischer and co-workers [13, 14]. Since these solvents worked well on instruments that use desolvation capillaries [I Iewletl-Packard (Palo Alto, CA), Finnigan MAT (San Jose, CA)], while the Sciex uses an orifice (this article), we are cautiously exploiting these potential advantages. Our focus is also to obtain a reliable HPLC-UV trace so that peptides can be collected for high sensitivity sequencing at the $1-3$ pmol range. Up to now, only our reported solvent solutions provided a stable UV base line for high sensitivity application. 

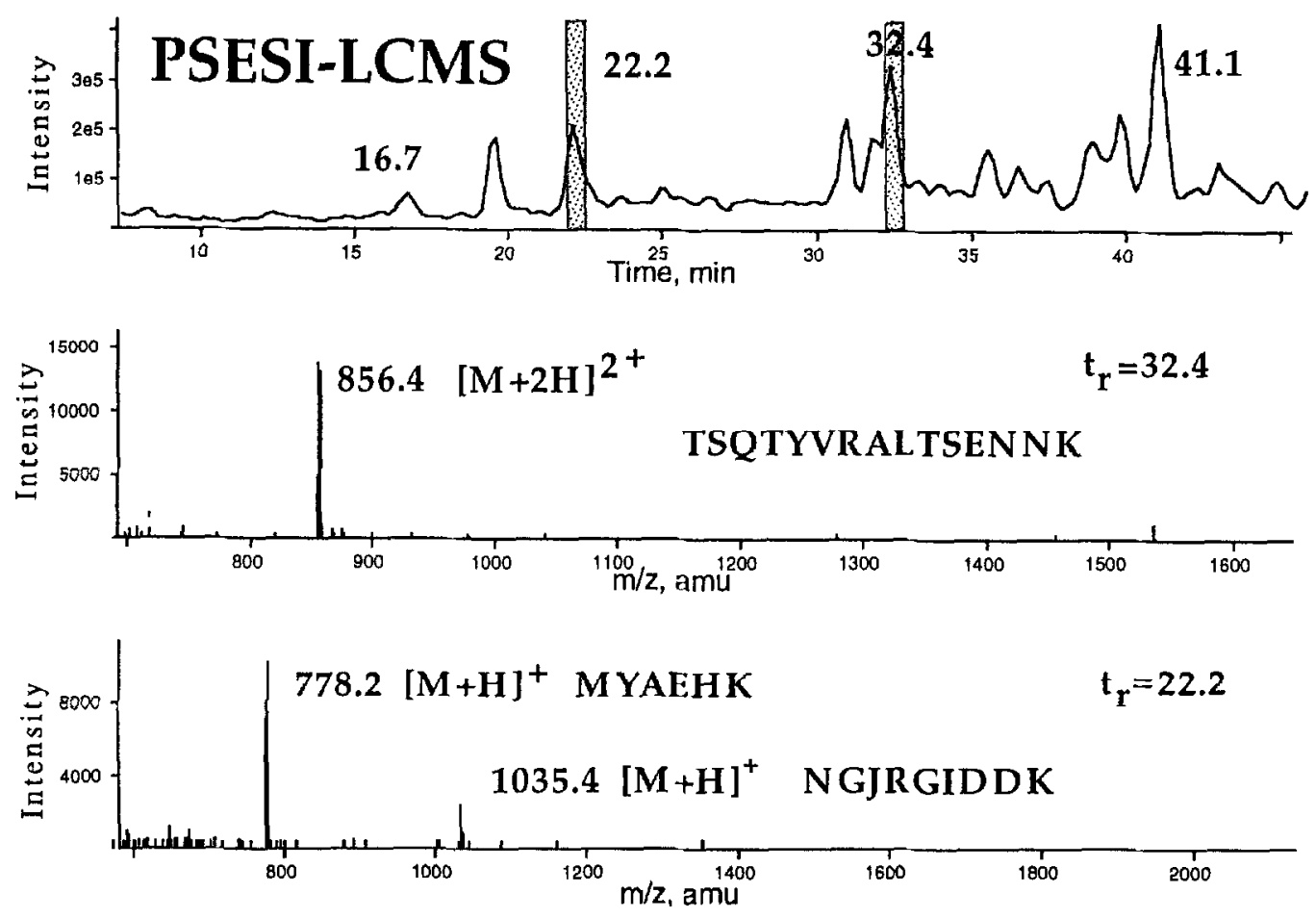

Figure 8. PSESI-LCMS mass spectra of peptides at $t_{r}=32.4$ min and $t_{r}=22.4 \mathrm{~min}$ where $[\mathrm{M}+$ $2 \mathrm{H}]^{2+}=m / z$ 856.4 (MW: $1711.8 \mathrm{Da}$ ) corresponding to residues (15-27), and $[\mathrm{M}+\mathrm{HH}]^{+}=m / z 778.2$ and $[\mathrm{M}+\mathrm{H}]^{+}=m / z$ 1035.4, corresponding to residues (1-6) and (62-68), respectively [7]. Carboxymethyl cysteine is denoted as "J."

\section{Conclusions}

We have demonstrated a versatile approach to deliver nanoliter flow rates to an electrospray ionization source. Most noticeably, there is neither modification of the HPLC nor the MS; the major portion of the sample $(>99 \%)$ can be collected fractionally for additional study such as Edman sequencing, a critical technique for the identification of peptides. Converting to PSESILCMS ( $150-850 \mathrm{~nL} / \mathrm{min}$ ) from conventional ESI-LCMS (40-80 $\mu \mathrm{L} / \mathrm{min}$ ) can be accomplished quickly, as the pneumatic splitter can also generate split flow rates up to $80 \mu \mathrm{L} / \mathrm{min}$. The pneumatic splitter can be modified inexpensively. This high sensitivity analysis of protein digest by PSESI-LCMS is a very simple and robust technique for implementation on most commercially available electrospray mass spectrometers.

In this article, we have focused our applications on narrow bore and analytical columns to demonstrate the diversity of this technique with the postcolumn splitting of the flow. The amounts of sample used in this article allowed for a comparison of the HPLC-UV trace with the corresponding PSESI-LCMS analysis. For this analytical HPLC system, the minimum requirement of the sample is $\sim 7 \mathrm{pmol}$. The use of this technique with the precolumn splitting flow of $\sim 250 \mathrm{~nL} / \mathrm{min}$ on capillary or microbore columns will be discussed in a later article. This latter approach requires several orders of magnitude less sample.

To the best of our knowledge, the use of a pneumatic splitter on an electrospray ionization source has not been previously reported.

\section{Acknowledgments}

The authors thank Anita Lavin, Scott Lauren, and Michael Jones for Edman sequencing and amino acid analyses. They also thank Dr. William Kenney for helpful suggestions. The preparation of this manuscript by Joan Bennett is also appreciated. Preliminary results of this investigation were presented at the 44th ASMS Conference on Mass Spectrometry and Allied Topics, Portland, OR, May 12-16, 1996.

\section{References}

1. Fenn, J. B.; Mann, M.; Wang, C. K.; Wong, S. F.; Whitehouse, C. M. Science 1989, 246, 64-71.

2. Andren, P. E.; Emmett, M. R.; Caprioli, R. M. J. Am. Soc. Mass Spectrom. 1994, 5, 867-869.

3. Wilm, M. S.; Mann, M. Int. J. Mass Spectrom. Ion Processes 1994, $136,167-180$.

4. Valaskovic, G. A., Kelleher, N. L.; Little, D. P.; Aaserud, D. J.; McLafferty, F. W. Anal. Chem. 1995, 67, 3802-3805.

5. Ito, Y.; Takeuchi, T.; Ishii, D.; Goto, M. J. Chromatogr. 1985, 161, 346.

6. Medzihradszky, K. F; Maltby, D. A.; Hall, S. C; Settineri, C. A.; Burlingame, A. L. J. Am. Soc. Mass Spectrom. 1994, 5, 350-358.

7. Hui, J.; Meng, S.; Katta, V.; Tsai, L.; Rohde, M.; Haniu, M. Techn. Protein Chem. 1995, VI, 341-348.

8. Wilm, M.; Schevchenko, A.; Houthaeve, T.; Breit, S.; Schweigerer, L.; T. Fotsis.; Mann, M. Nature 1996, 379, 466-469. 
9. Davis, T. M.; Stahl, C. D.; Hefta, A. S.; Lee, D. T. Anal. Chem. $1995,67,4549-4556$.

10. Emmett, M. R.; Caprioli, R. M. J. Am. Soc. Mass Spectrom. 1994, $5,605-613$.

11. Carr, S. A.; Huddleston, M. J.; Bean, M. F. Protein Sci. 1993, 2, 183.
12. Stone, K. L.; Elliott, J. I.; Peterson, G.; McMurray, W.; Williams, K. R. Methods Enzymol. 1990, 193, 389.

13. Kuhlmann, F.E.; Apffel A.; Fischer, S. M.; Goldberg, G.; Gooley, P. C. I. Am. Soc. Mass Spectrom. 1995, 6, 1221-1225.

14. Apffel, A.; Fischer, S.; Goldberg, G.; Gooley, P.; Kuhlmann, F. J. Chrom. A 1995, 712, 177-190. 